\section{Does sulphoxidation state predict gold toxicity in rheumatoid arthritis?}

Gold (sodium aurothiomalate) is commonly used as a disease modifying agent in rheumatoid arthritis. Its use is, however, limited by occurrence of toxic reactions, which may develop in up to $45 \%$ of patients. ${ }^{1}$ The mechanism of toxicity is not clear, although a genetic basis for haematological and renal toxicity has been shown. ${ }^{2}$ Penicillamine and captopril are also effective disease modifying drugs and share a similar toxicity profile to sodium aurothiomalate. ${ }^{3}$ All three drugs have in common a sulphydryl group: their toxicity and efficacy may be due to parent sulphydryl groups or a toxic metabolite of oxidation of sulphur.

The oxidation of some sulphydryl groups is thought to be mediated by a hepatic flavoprotein oxidase. ${ }^{4}$ The ability of this or an associated enzyme system to handle sulphydryl groups seems to correlate with ability to oxidise sulphur, as measured by the ratio of free sulphides to sulphoxides after a fixed oral dose of carbocisteine (another drug containing sulphur); this ratio is the sulphoxidation index. Patients with rheumatoid arthritis with a poor sulphoxidation state are more susceptible to penicillamine toxicitys; we assessed whether they are also more susceptible to sodium aurothiomalate toxicity.

\section{Patients, methods, and results}

We studied 30 randomly selected patients with classical or definite rheumatoid arthritis who had received sodium aurothiomalate; 14 had developed a toxic reaction, while the remaining 16 had received sodium aurothiomalate for more than one year without adverse effect. After an overnight fast each patient received $750 \mathrm{mg}$ carbocisteine (Mucodyne, Berk); after one hour patients were given their daily medication and allowed to eat freely. All urine passed for eight hours was collected, the volume recorded, and a $10 \mathrm{ml}$ aliquot stored at $-4^{\circ} \mathrm{C}$.

The urine was analysed for the sulphide and sulphoxide metabolites of carbocisteine by paper chromatography; compounds were visualised by the chloroplatinate reaction and measured by planimetric densitometry. ${ }^{4}$ The sulphoxidation index was derived from the ratio of excreted sulphides to sulphoxides. A value $>6$ was taken as indicating an impaired ability to metabolise carbocisteine (poor sulphoxidation state) and $\leqslant 6$ a good ability to handle carbocisteine.

Of the 14 patients who had suffered adverse reactions, 13 had a low sulphoxidation index (table); their reactions comprised proteinuria (four patients), thrombocytopenia (two), leucopenia (two), and mucocutaneous reactions (five). Only one of the nine patients with a low sulphoxidation index had

Toxicity related to sulphoxidation state

\begin{tabular}{lccc}
\hline & \multicolumn{2}{c}{ Sulphoxidation state } & \\
\cline { 2 - 3 } & Poor & Good & Total \\
\hline Patients with toxicity & 13 & 1 & 14 \\
Patients without toxicity & 8 & 8 & 16 \\
\hline Total & 21 & 9 & 30 \\
\hline
\end{tabular}

Fisher's exact test, $\mathrm{p}<0 \cdot 02$

developed an adverse reaction-namely, mouth ulceration $(p<0.02$, Fisher's exact test (two tailed)). The relative risk of a patient with a poor sulphoxidation state developing a toxic reaction was 5.9. In those with a poor sulphoxidation state there was no apparent relation between the degree of impairment of sulphoxidation and type of toxicity.

\section{Comment}

This study is the first to show that patients with an impaired ability to metabolise carbocisteine are predisposed to sodium aurothiomalate toxicity. The relative risk is similar to that found for penicillamine. In a previous study haematological and renal toxic reactions to sodium aurothiomalate were strongly associated with major histocompatibility type HLA-DR3. ${ }^{2}$ A preliminary study, however, suggested that poor sulphoxidation state and HLA-DR3 were independent, so both variables may need to be considered. ${ }^{5}$

An interesting additional observation in our study was the unexpectedly high prevalence of patients with a poor sulphoxidation state (67\%) compared with the proportion in the general population $(22 \%)^{4}$; this observation needs to be confirmed in an unselected patient population to exclude selection bias. If our findings are confirmed in a cohort of patients treated prospectively with sodium aurothiomalate then sulphoxidation state should prove to be useful in improving the risk:benefit ratio of sodium aurothiomalate in rheumatoid arthritis; it may also be an interesting pharmacogenetic probe into the pathogenesis of rheumatoid arthritis.

1 Kean WF, Anastassiades TP. Long term chrysotherapy: incidence of toxicity and efficacy during sequential time periods. Arthritis Rheum 1970;13:495-501.

2 Wooley PH, Griffin J, Panayi GS, et al. HLA-DR antigens and toxic reaction to sodium aurothiomalate and D-penicillamine in patients with rheumatoid arthritis. $N$ Engl $\mathcal{J}$ Med 1980;303:300-2.

3 Martin MFR, Surrall K, McKenna F, et al. Captopril-a potential new treatment for rheumatoid arthritis. Lancet 1984;i:1325-7.

4 Waring RH, Mitchell SC, Shah RR, et al. Polymorphic sulphoxidation of S-carboxymethyl-L-cysteine in man. Biochem Pharmacol 1982;31:3151-4.

5 Emery P, Panayi GS, Huston G, et al. D-Penicillamine induced toxicity in rheumatoid arthritis: the role of sulphoxidation status and HLA-DR3. F Rheumatol 1984;11:626-32.

(Accepted 20 November 1986)

Centre for Rheumatic Diseases, Glasgow Royal Infirmary, Glasgow G4 0SF RAJAN MADHOK, MB, MRCP, registra

HILARY A CAPELL, MB, FRCP, consultant physician

Department of Biochemistry, University of Birmingham

ROSEMARY WARING, PHD, senior lecturer

Correspondence to: Dr Madhok.

\section{Acute pancreatitis: a new finding in cryptosporidium enteritis}

Cryptosporidium is a coccidian parasite that, since its first description in man in 1976, has become increasingly recognised as a cause of acute enterocolitis. ${ }^{1}$ It has also, however, been recovered from the lung ${ }^{2}$ and gall bladder ${ }^{3}$ as well as from the pancreatic duct. ${ }^{4}$ We report on a patient with cryptosporidial enteritis and acute pancreatitis.

\section{Case report}

A previously healthy 14 year old farmer's daughter was admitted to hospital in May 1986 with acute abdominal pain. One week before admission she had developed diffuse colicky abdominal pain associated with anorexia, nausea, vomiting, watery diarrhoea, and a temperature of $39^{\circ} \mathrm{C}$. These symptoms resolved after four days. A faecal specimen submitted by her general practitioner contained large numbers of cryptosporidium oocysts. On the day of admission her abdominal pain recurred and worsened. She did not have a history of recent abdominal trauma or familial pancreatitis.

On examination she was pale, dehydrated, and obviously in pain, but afebrile. Her abdomen was soft with tenderness and guarding centrally and over the epigastrium. Bowel sounds and the results of rectal examination were normal. Gastroenteritis was initially diagnosed. Investigations showed: haemoglobin 131 $\mathrm{g} / \mathrm{l}$, white cell count $29 \cdot 1 \times 10^{9} / \mathrm{l}$, blood glucose $10.5 \mathrm{mmol} / \mathrm{l}$, serum amylase 14400 (normal $<300$ ) U/l, calcium $2.3 \mathrm{mmol} / \mathrm{l}$, and normal concentrations of urea and electrolytes. The results of serological tests for antibodies to influenza $A$ and B, adenovirus, Chlamydia psittaci, Mycoplasma pneumoniae, Coxiella burnetii, measles, mumps, varicella zoster, cytomegalovirus, respiratory syncitial virus, and coxsackie B were all negative. Markers for hepatitis A and B were no detected. Serum cholesterol, high density lipoprotein, and low density lipoprotein concentrations were not increased. Autoantibodies were not detected. Cryptosporidium specific antibody titres obtained by a fluorescence antibody test were consistent with recent infection. A chest $x$ ray film showed some bilateral basal consolidation with bilateral effusions while an abdominal $x$ ray film was normal. Acute pancreatitis was diagnosed, and intravenous fluid replacement and nasogastric aspiration were started. Abdominal ultrasound showed enlargement of the pancreas and ascites. A repeat faecal examination showed a reduction in the number of cryptosporidium oocysts; none could be detected after one week.

She recovered slowly and became asymptomatic after two weeks. Though an ultrasound scan showed a pancreatic pseudocyst $5.5 \mathrm{~cm}$ in diameter she was allowed home. At six weeks it had almost resolved. Increased pancreatic echogenicity at this time suggested the possibility of chronic pancreatitis. Gall stones were not identified. Though the patient remained well her progress was monitored, and she had an endoscopic retrograde cholangiopancreatographic examination.

\section{Comment}

The method of transmission of cryptosporidium is still debatable. It was originally thought to be zoonotic, but recent work suggests that person to person transmission is common (D Casemore, personal communication). Our patient worked with her parents' cattle and drank untreated milk: both are considered to be possible sources of infection. 
Most reports of cryptosporidium enteritis have described an association with the acquired immune deficiency syndrome and a limitation to the gastrointestinal tract. Subsequently the disease has occurred in patients with a normal immune system and in other organs, suggesting possible haematogenous spread.

This patient presented with typical gastroenteritis except for the severity of the abdominal pain. Cryptosporidium causes more intense abdominal pain than Giardia lamblia, and cramps are more common. ${ }^{5}$ Although our patient may be an isolated example, we wonder whether some infected patients who complain of severe pain may be suffering from acute pancreatitis. We suggest therefore that cryptosporidium may be an additional aetiological factor in the cause of acute pancreatitis.

We thank Dr S Reilly and Dr P J Wilkinson, Derriford Hospital, Plymouth, and Mr D Casemore, Rhyl Public Health Laboratory.

1 Jokipii L, Pohjola S, Jokipii AMM. Cryptosporidium: a frequent finding in patients with gastrointestinal symptoms. Lancet 1983:ii;358-61.

2 Forgacs $\mathrm{P}$, Tarshis A, Ma P, et al. Intestinal and bronchial cryptosporidodiosis in an immunodeficient homosexual man. Ann Intern Med 1983;99:793-4.

3 Pitlik SD, Faundstein V, Guarda L, et al. Human cryptosporidiosis spectrum of disease. Arch Intern Med 1983;143:2269-7.

4 Kocoshis SA, Cibull ML, Davies TE, et al. Intestinal and pulmonary cryptosporidiosis in an infant with severe combined immune deficiency. F Pediatr Gastroenterol Nutr 1984;3:149-57.

5 Casemore DP, Sands RL, Curry A. Cryptosporidium species: a "new" human pathogen. $f$ Clin Pathol 1985;38:1321-36.

(Accepted 13 October 1986)

\section{Derriford Hospital, Plymouth PL6 8DH}

S P HAWKINS, MB, BS, house officer

R P THOMAS, FIMLS, senior medical laboratory scientific officer

C TEASDALE, MS, FRCS, consultant surgeon

Correspondence to: Dr S P Hawkins, Department of Geriatric Medicine, St Woolos Hospital, Newport, Gwent NP9 4SZ.

\section{Isolation of human immunodeficiency virus from synovial fluid of a patient with reactive arthritis}

With the increasing prevalence of the acquired immune deficiency syndrome (AIDS) and seropositivity to human immunodeficiency virus (HIV) health workers need to be cautious in handling body fluids. We report on a patient in whom HIV was isolated from synovial fluid aspirated from a knee joint.

\section{Case report}

A 37 year old homosexual man presented with a four day history of profuse watery diarrhoea followed, after seven days, by migratory joint pains. On admission he was feverish (temperature $37.8^{\circ} \mathrm{C}$ ) and had appreciably reduced neck movements, bilateral knee effusions, and tender wrists. On investigation his haemoglobin concentration was $116 \mathrm{~g} / \mathrm{l}$, white cell count $5.9 \times 10 \mathrm{~g} / \mathrm{l}$, and $\mathrm{C}$ reactive protein concentration $66 \mathrm{mg} / 1$ (normal $<5 \mathrm{mg} / \mathrm{l}$ ). Routine blood, stool, and urine cultures yielded negative results, as did a test for hepatitis B surface antigen and a Monospot test. Antibodies to Chlamydia trachomatis were not found. IgG antibody to HIV was detected by enzyme linked immunosorben assay and indirect membrane immunofluorescence in serum obtained one week before his admission to hospital. A subsequent sample was shown to contain IgG and IgM antibodies by indirect membrane immunofluorescence. Antibody to Salmonella paratyphi was present at a titre of $1 / 640$. The erythrocyte sedimentation rate before admission was $64 \mathrm{~mm}$ in the first hour. $x$ Ray pictures were normal. Synovial fluid aspirated from the right knee was mildly cloudy and straw coloured. It contained IgG but not IgM antibody to HIV.

Isolation of virus-The virus was isolated by two culture methods: a small volume of synovial aspirate (A) was cocultured with normal peripheral blood lymphocytes stimulated by phytohaemagglutinin, the ratio of synovial cells to lymphocytes being $1: 3^{1}$; and a second culture (B) was established with Hut 78 cells. Viral growth was detected by observation of cytopathic effects, immunofluorescence, and reverse transcriptase assays. ${ }^{2}$ After 11 days infectious retrovirus was identified in culture $\mathrm{A}$ by a peak in particle associated reverse transcriptase activity in the supernatant fluid (figure). Synctial formation was noted in culture B after 20 days, and four days later viral antigens were detected by indirect membrane immunofluorescence.

The patient was treated with bed rest, anti-inflammatory drugs, and a continuing course of tetracycline. He had an intermittent fever at night, and 10 days later lymph nodes in both axillas and inguinal regions were palpable. His joint symptoms had improved before his discharge from hospital.

\section{Comment}

Although no retrovirus has been implicated in the pathogenesis of arthritis in man, a member of the same subfamily as HIV, caprine arthritis encephalitis virus, causes arthritis in goats. ${ }^{3}$ Though patients with AIDS commonly complain of arthralgia, arthropathy has not been described; in this case there was no direct evidence that HIV was the cause of the arthritis. Possibly our patient was suffering from a reactive arthritis and lymphocytes invading the inflamed knee joint were infected with HIV. The clinica presentation of the joint manifestations was not, however, typical of a reactive arthritis: the pronounced neck stiffness and tenderness of the cervical spine on palpation and thereafter were unusual. The lack of stiffness

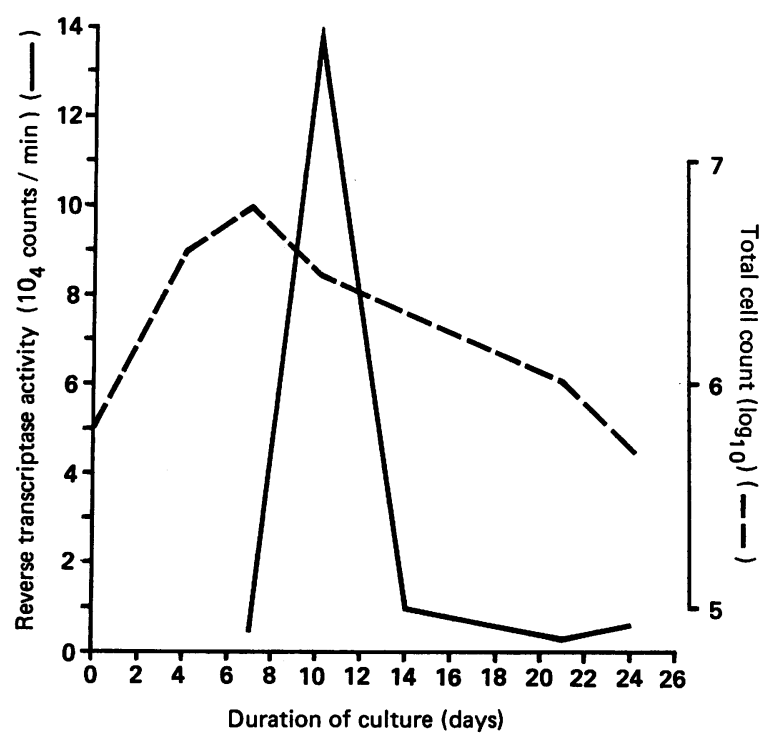

Reverse transcriptase activity in cultured synovial aspirate, and total cell count.

on neck flexion and the relative lack of tenderness associated with lymphadenopathy further supported the diagnosis of arthritis affecting the cervical spine. Whether HIV can cause arthritis must, we believe, remain an open question.

The isolation of HIV from synovial fluid is important for those dealing with patients suffering from reactive arthritides of whatever cause. It re-emphasises the need to apply safety precautions whenever exposure to body fluid is likely, and it raises the question whether it is appropriate to use intra-articular steroids in patients who are positive for antibody to HIV.

We thank Drs J P Getchell and D R Hicks and Ms J L Heath for the Hut 78 subclone (6D5); Dr V S Kalyanaraman for the CDC 451 virus isolate; Dr B Thomas for undertaking the microimmunofluorescence test to detect antibodies to Chlamydia trachomatis; and Miss D Gor for technical help.

1 Wofsy CB, Cohen JB, Hauer LT, et al. Isolation of AIDS-associated retrovirus from genital secretions of women with antibodies to the virus. Lancet 1986; i:527-9.

2 Hoffman AD, Banapour B, Levy JA. Characterisation of the AIDS associated retrovirus reverse transcriptase and optimal conditions for its detection in virions. Virology 1985;147:326-35. 3 Crawford TB, Adams DS, Cheevers WP, Cork LC. Chronic arthritis in goats caused by a retrovirus. Science 1980;207:997-9.

(Accepted 22 October 1986)

\section{St Mary's Hospital, London W2}

ROBIN H WITHRINGTON, BA, MRCP, senior registrar, department of rheumatology

PAUL CORNES, BA, BM, senior house officer, department of rheumatology

J R WILLIE HARRIS, BM, FRCP, consultant physician, Praed Street clinic

MARTIN H SEIFERT, MB, FRCP, consultant physician, department of rheumatology

St Mary's Hospital Medical School, London W2

ELEANOR BERRIE, PHD, postdoctoral research worker, Jefferiss research wing

DAVID TAYLOR-ROBINSON, MD, FRCPATH, director of Jefferiss research wing

DONALD J JEFFRIES, MB, FRCPATH, consultant virologist, department of virology

Correspondence to: Dr Seifert. 